\title{
REVISITANDO LA DISCUSIÓN ENTRE AUGUSTO SALAZAR BONDY Y LEOPOLDO ZEA. LA FILOSOFÍA LATINOAMERICANA: EL LUGAR DE UN DIFERENDO ${ }^{1}$
}

\author{
Cristóbal Friz Echeverría \\ Universidad de Santiago \\ cristobal.frize@usach.cl
}

\begin{abstract}
RESUMEN / ABSTRACT
El artículo revisita la discusión entre Augusto Salazar Bondy y Leopoldo Zea hacia fines de la década de 1960 sobre la filosofía latinoamericana, con el objetivo de mostrar que la misma es el lugar de un diferendo: de pugna entre posiciones y representaciones disímiles, en algunos casos irreconciliables. Como se propone, lo que está en disputa en tal controversia, es el significado de la filosofía y de lo filosófico, en contextos de enunciación como América Latina. Para ello, se recorren diversos núcleos conceptuales de la disputa, mostrándola como una discusión filosófica aún vigente.
\end{abstract}

Palabras Clave: filosofía, América Latina, compromiso político-intelectual, tradición, proyecto, identidad, universalidad, desplazamientos categoriales.

\section{REVISITING THE DISCUSSION BETWEEN AUGUSTO SALAZAR AND LEOPOLDO ZEA}

This paper aims the discussion between Augusto Salazar Bondy and Leopoldo Zea about lateinamerican philosophy, that takes place towards the end of the 1960s. The objective is to show that this discussion is the place of a differendum; that means, of conflict between dissimilar positions and representations, in some cases irreconcilable. As proposed, what is discussed in that controversy is the meaning of philosophy and the philosophical, in contexs of enunciation such Latin America. For this, we review some conceptual nuclei of the dispute, showing it as a current philosophical discussion.

KEYWoRDS: Philosophy, Latin America, Political-intellectual engagement, Tradition, Project, Identity, Universality, Conceptual displacements. 


\section{A 50 años: Inactualidad y actualidad de una disputa}

R⿴囗十 En 2018 se cumplen 50 años de la publicación de ¿Existe una filosofia de nuestra América? (1968) del peruano Augusto Salazar Bondy (1925-1974), libro que generó una serie de respuestas y reacciones entre filósofos y estudiosos del pensamiento latinoamericano, de las cuales la más conocida es la del mexicano Leopoldo Zea (19122004), La filosofía americana como filosofía sin más (1969) ${ }^{2}$. ¿Por qué volver a esta polémica, la que ha sido profusamente estudiada y comentada ${ }^{3}$, y que acaso debiéramos considerar añeja y superada? ${ }^{4}$

Son múltiples las respuestas que podríamos esbozar: reparar, por ejemplo, en la inflexión que comportó la disputa para el campo disciplinar de la historia de las ideas

2 En este trabajo referimos la decimotercera edición del libro de Salazar Bondy (1996) y la decimosexta del de Zea (1996).

3 Sobre los comentarios y estudios de la discusión cabe destacar, cercanos cronológicamente a la misma: Cerutti Guldberg (2006, primera edición de 1983), Gallardo (1974), Olmedo (1972), Santos (1977). Posteriormente, Arpini (2003, 2016), además de múltiples obras sobre el pensamiento filosófico latinoamericano en que la misma tiene un lugar señalado; por ejemplo, Santos Herceg (2010).

La discusión sobre la existencia de una filosofía latinoamericana, en términos familiares a los planteados por Salazar y Zea en las obras mencionadas se remonta a los seminarios organizados por el hispano-mexicano José Gaos (1900-1969) desde el comienzo de su exilio en México en 1938 -a los que asisten ambos autores-, donde promueve el estudio de la filosofía y el pensamiento en lengua española, en que Gaos incluye al pensamiento latinoamericano. Como puntualiza Dante Ramaglia, los principales ejes de discusión en la filosofía latinoamericana a mediados del siglo XX son, entre otros, la preocupación por la "originalidad", la "autenticidad" y la "identidad cultural" (Ramaglia 2009, p. 382), los que tienen lugar destacado en las obras de Salazar Bondy y Zea que acá nos ocupan.

Debe tenerse presente que, según clarifica Horacio Cerutti, la respuesta de Zea en su libro La filosofía americana como filosofía sin más es solo el inicio de la polémica, la que rebasará a los textos y a los autores. Ambos volverán a la misma en el Simposio de Filosofía Latinoamericana que tiene lugar en San Miguel, Buenos Aires, en la Universidad del Salvador en agosto de 1973, donde, como señala Manuel Ignacio Santos, "se sometió a discusión el problema de una filosofía latinoamericana como filosofía de la liberación" (Santos 1977, p. 19). Tras la muerte de Salazar Bondy en 1974, ese mismo año Zea escribe un artículo en el que, según Cerutti, da por terminada la polémica, respetando el hecho de que Salazar ya no pudiera dar respuesta a sus planteamientos (Cerutti Guldberg 2006, pp. 268-272). No obstante estas importantes indicaciones, aquí nos detendremos exclusivamente en los ejes de la polémica consignados en los libros de 1968 y 1969, por considerar que en ellos queda establecido el ámbito de problematicidad fundamental de la discusión entre ambos autores.

4 José Santos Herceg habla, por ejemplo, de una "añeja y ya desperfilada disputa acerca de si existe o no un pensamiento filosófico latinoamericano" (Santos Herceg 2012, p. 67), lo que se complementa y explica con el parecer de Dante Ramaglia, para quien ya no se discute dicha existencia dado el carácter manifiesto de sus expresiones relevantes (Ramaglia 2009, p. 397). 
latinoamericanas (Arpini 2003, 2016); o en la importancia decisiva de la misma para la constitución de la "filosofía latinoamericana de la liberación" (Cerutti Guldberg 2006, Santos 1977); o en su impronta para el planteamiento del "problema de la conformación de nuestra conciencia" (Gallardo 1974). No obstante, sin desatender ni desestimar estos y otros motivos posibles, interesa acá prestar atención a la indicación de Arturo Roig respecto de la importancia de estudiar a "nuestros clásicos" latinoamericanos (Roig 2009).

Siguiendo esta indicación de Roig, si los planteamientos de Salazar y Zea tienen algo de clásicos, tal disputa tendría alguna relevancia en la actualidad: algo que decirnos a nosotros; alguna pista respecto de algo sobre lo que debiéramos volver, una y otra vez, a pensar. Esto puede ser particularmente válido para Chile, donde la tradición latinoamericana -y de un modo genérico, toda tradición distinta que la europeo-occidental-se halla aún en pugna por su incorporación y reconocimiento en lo que la institucionalidad universitaria sanciona como lo filosófico.

En efecto, y como se mostrará a lo largo de este escrito, aquello disputado por los autores es justamente el estatuto de la filosofía y lo filosófico: el significado y sentido de la actividad filosófica, y las posibilidades de la misma en contextos de enunciación distintos a los de Europa occidental. Interesará, por lo tanto, exponer esta disputa como una discusión propiamente filosófica, que en cuanto tal nos conmina a pensar. Y por tratarse de una controversia sobre el estatuto de lo filosófico, interesará revisitarla en sus núcleos conceptuales, poniendo de manifiesto que ella es el lugar de un diferendo: de pugna entre posiciones y representaciones disímiles, en algunos casos irreconciliables.

\section{Contexto y coordenadas de la discusión: entre filosofía profesional y compromiso político-intelectual}

Como toda producción teórica, la discusión de Salazar Bondy y Zea supone un complejo entramado de influencias y discursos, además de ser expresión y respuesta a un determinado ánimo epocal. No me detendré acá en el tema de las influencias, o en la actualidad de las lecturas de los autores, salvo en la medida en que sea necesario para la presente exposición (estas cuestiones, por lo demás, han sido trabajadas en la literatura que ha abordado la disputa).

Se tratará, más bien, de inscribir la controversia en una doble coordenada discursiva y epocal, la que, como se procurará mostrar, comporta una serie de tensiones y complejidades que atraviesan sus modos de enunciación, las condiciones de posibilidad de la discusión misma y de lo que en ella se entiende (o puede entenderse) por filosofía, y por filosofía latinoamericana. La coordenada propuesta, como se mostrará, está configurada por el cruce de dos ejes: la profesionalización de la filosofía como actividad universitaria y la asunción del ejercicio filosófico como quehacer comprometido políticamente.

El primer eje dice relación con lo que el hispano-argentino Francisco Romero (18911962) denominó, para referir el desarrollo de la filosofía en los países hispanoamericanos desde fines de los 30 y la década del 40, como "normalidad filosófica" (o también 
“normalización filosófica") (cf. Romero 1952)5. Para Romero, esta nueva etapa comporta, a diferencia de las anteriores, el asentamiento de las condiciones institucionales e intelectuales -es decir, el cultivo de la filosofía como labor profesional universitaria, y una sólida formación filosófica- para el "normal" despliegue del filosofar en la región; es decir, para su incorporación como una "función normal de la cultura".

Normalidad filosófica, como ponen de manifiesto Carlos Ossandón (1984) y José Santos Herceg (2010), es una noción fuertemente normativa y problemática. Por una parte, comporta la identificación de filosofía con filosofía universitaria, según el parámetro de la filosofía occidental contemporánea, lo que con Cecilia Sánchez conduce a la escisión entre un filosofar mundano y uno académico, entre los tiempos del mundo y el tiempo de la teoría (Sánchez 1992) ${ }^{6}$. Junto con ello, la normalización supone que nuestra "vocación filosófica" adquiere "conciencia de sí". Esto se pone de manifiesto, además de en la interrogante por su historia, en la pregunta por su estatus y sus posibilidades (su "autenticidad" y "originalidad", por ejemplo), por sus relaciones con la realidad en que se inserta, con la tradición occidental, etc.

El segundo eje atañe a la sensibilidad sesentista en América Latina, la que pone en tensión el eje normativo de la normalidad filosófica, al tiempo que, con él, comparece como trasfondo de la discusión de Salazar Bondy y Zea, y funge de contexto de emergencia del pensamiento liberacionista latinoamericano contemporáneo ${ }^{7}$. Este ánimo epocal, cuyo hito de apertura es según Eduardo Devés la Revolución cubana del 59, y que tiene por cierre el golpe de Estado del 73 en Chile -razón por la que cabe hablar de unos "largos 60 "-, es rubricado por este autor bajo la consigna "todo es política".

5 La caracterización de la "normalidad filosófica" aquí desarrollada se remite principalmente al estudio de Carlos Ossandón (1984). Para este proceso en el caso argentino, véase Ramaglia (2007).

$6 \quad$ Según Sánchez, en Chile serían Pedro León Loyola (1889-1978) y Enrique Molina (18711964) quienes asentarían las bases de la "institucionalización universitaria de los estudios filosóficos", en función de la idea de una cierta "autonomía" del ejercicio filosófico respecto de otros campos, particularmente el político.

Sumamente esclarecedoras son las declaraciones de Enrique Molina a comienzos de la década de 1950, donde señala que figuras como Andrés Bello, José Victorino Lastarria, Francisco Bilbao o Valentín Letelier no son filósofos propiamente tales. "Todos éstos -comenta Molina- habían dedicado, sin duda, desvelos a la filosofía; pero vivían ante todo absorbidos por los problemas sociales y políticos y por el afán de atender al progreso y reestructuración de la colectividad". La filosofía, para Molina, comprende exclusivamente "las disciplinas que dicen relación con la indagación del ser y con la actitud del hombre ante él". Solo quien se ocupa de ellas es, en su opinión, "un especialista de la filosofía (...) lo que se llamaría un filósofo en nuestros días" (Molina 1953, 9-10, 22).

7 En el contexto de este estudio, interesa inscribir la discusión de Salazar Bondy y Zea en los comienzos o detonantes de la "filosofía de la liberación latinoamericana", únicamente en la medida en que ésta comporta la adopción expresa de un compromiso político-intelectual por parte del quehacer filosófico en la región. Para este tema véase, entre otros, Cerutti Guldberg (2006) y Santos (1977). 
Dicha sensibilidad -que, en lo que acá interesa, supone que el ejercicio intelectual puede y debe cumplir un rol importante en la comprensión y superación de las condicionantes sociales estructurales que aquejan a los países latinoamericanos, y de modo genérico, a los del denominado tercer mundo- bebe de distintas fuentes.

Entre ellas cabe destacar algunas escuelas filosóficas europeas (la fenomenología, el existencialismo, el marxismo; es importante aquí la figura de Sartre como intelectual comprometido) y los planteamientos de Paulo Freire y de la teología de la liberación. Asimismo es importante el influjo de los movimientos de decolonización (bajo la figura central de Frantz Fanon) y de los postulados de las ciencias económico-sociales latinoamericanas; puntualmente, la teoría de la dependencia. Esta última viene a complementar el análisis de clase, de raigambre marxista, con el análisis colonial, postulando que es el propio desarrollo o modernización capitalista-analizado bajo el par categorial metrópoli/satélite- el que ha subdesarrollado a América Latina, comportando un colonialismo e imperialismo no solo económico, sino también cultural y mental: una “ideología de dominación” (Devés 2003-2004, Tomo II, Parte V, cap. I-III).

Según lo ya mencionado, considero que esta doble coordenada -profesionalización universitaria del ejercicio filosófico versus compromiso intelectual con la transformación de la realidad-cruza y tensiona los textos de Salazar Bondy y Zea, atravesando no solo los términos y modos de enunciación de la discusión, sino también las posibilidad de la misma, y de lo que en ella se entiende (o puede entenderse) por filosofía, y por filosofía latinoamericana. A esta doble coordenada se refería Horacio Cerutti a comienzos de los 80 cuando afirmaba que "la polémica es uno de los eslabones centrales del pensar filosófico actual en América Latina”; y que la misma trascendía a los autores y se mantenía abierta, por estimar que lo que en buena medida está en juego en ella es "la correlación de filosofía y política que es en definitiva fiel en esto a una larga tradición en nuestra América, el problema central que sigue estando en cuestión" (Cerutti Guldberg 2006, pp. 272-273)

Dicho lo anterior, el análisis se centrará en tres puntos o momentos fuertemente interrelacionados que parecen particularmente significativos para ponderar la importancia y los alcances (eventualmente actuales) de la querella. En primer lugar, en la pregunta de si la filosofía latinoamericana es una labor que cuenta con una tradición, o si bien es una empresa prospectiva por realizar. En segundo término, en la disyuntiva entre un identitarismo cultural y filosófico al que debiera adscribir la labor filosófica local, y la opción por inscribirla en la presunta universalidad de la cultura y el pensar occidental. Finalmente, en el que es probablemente el punto más delicado -por lo tanto más

8 Igualmente claro al respecto es Helio Gallardo, quien a propósito de la disputa sostiene: "Tras la pregunta por la existencia de una filosofía latinoamericana suele, en ocasiones, esconderse una intención militante"; y que "la pregunta por la posibilidad de nuestra filosofía se inserta dentro del cuadro general de un mundo que lucha por la liberación y la independencia solidaria del hombre". Es importante destacar que, para Gallardo, dicha intención debe asentarse en un "trabajo filosófico" serio y riguroso. (Gallardo 1974, p. 209) 
sugestivo y productivo- del debate, concerniente a los desplazamientos categoriales presentes en la respuesta de Zea; lo que en un extremo puede conducir a la pregunta de si éste responde propiamente a Salazar Bondy y, por lo tanto, si efectivamente podemos hablar de una discusión o un diálogo entre ambos autores.

\section{Filosofía latinoamericana, ¿tradición o proyecto?}

Según Marcos García de la Huerta, como quiera que se plantee y se entienda, la pregunta por la filosofía latinoamericana debe comprenderse como una interrogante por una identidad cultural en el plano filosófico; como intento de afirmación de una identidad regateada por la conquista, la colonización y la herencia cultural eurocéntrica, que se procura asentar o proyectar en el ámbito del pensamiento (García de la Huerta 2014, p. 77, 1999). Esto se condice con la tesis de Eduardo Devés, según la cual el pensamiento latinoamericano, tanto en el siglo XIX como en el XX, se debate entre la modernización y la identidad (Devés 2003-2004), es decir, entre el ajuste o puesta al día de los países latinoamericanos con los parámetros promovidos por Occidente y la afirmación de lo "propio" o "particular".

Entrando a las obras que aquí nos ocupan, un primer punto en que se puede registrar este intento de vindicación identitaria es la interrogante respecto de si la filosofía latinoamericana es una labor que cuenta con antecedentes asentados en una tradición que podamos asumir y reconocer como "propia", a la que habría que acudir mediante un ejercicio de memoria reflexiva que apunta a su proyección a futuro; o si bien es una labor que adopta la forma de un proyecto, lo que en una acepción extrema supone entenderla como labor meramente prospectiva, la que solo encontraría en el pasado una fuente de errores que indicarían las vías infecundas por las que no se debe volver a transitar.

A este extremo se refería Humberto Giannini al indicar que la historia americana se halla cruzada por un "gesto fundacional". En sus palabras: "El gesto fundacional se prolonga por la historia americana como un ritual, casi como un automatismo: la obsesión de estos pueblos de empezar cada cierto tiempo de cero, todo da capo; en política, en educación, en economía; la obsesión de lo discontinuo y de no dejar rastros tras sí, como si sólo a través de la destrucción pudiera construirse algo. Un antiplatonismo natural. Diríamos, el olvido como técnica para avanzar. El horror al pasado" (Giannini 2004, p. 74, nota).

Con todos los recaudos y matices necesarios, podemos rubricar la perspectiva de Salazar Bondy en este gesto fundacional, toda vez que su diagnóstico sobre la historia y el presente (entiéndase, hacia fines de la década del 60) del filosofar hispanoamericano es fuertemente negativo. Esto se expresa en su afirmación de que son sumamente escasos -en caso de haberlos- los trabajos que dan cuenta de "la existencia de productos filosóficos hispanoamericanos originales, equiparables a los europeos" (Salazar Bondy 1996, p. 74). 
Este diagnóstico expresa ejemplarmente las tensiones entre profesionalización y compromiso político del quehacer filosófico. El diagnóstico, en efecto, se encuentra fuertemente condicionado por el concepto de filosofía con que opera el peruano, profundamente comprometido a su vez con la categoría romeriana de normalidad, conocida y suscrita por Salazar bajo la noción de "regularización", según la cual en los países hispanoamericanos ya se ha asentado una "actividad filosófica regular" (Ibíd., p. 19).

De hecho, en la introducción de su libro señala: “[S]ólo nos ocuparemos del pensamiento filosófico propiamente tal, y por tanto, no trataremos sino indirectamente de otras modalidades de lo que en forma genérica puede llamarse pensamiento ( $v$.gr. creencias religiosas, programas políticos, ideas artísticas, etcétera)" (Ibíd., p. 8). En virtud de este supuesto de trabajo, filosofía es y puede ser únicamente filosofía académica. Por ello, no es posible reconocer como "pensamiento filosófico propiamente tal" a otras modulaciones del filosofar que las elaboradas en la universidad; esto implica negar el estatuto epistemológico de filosofía, por ejemplo, a las obras de muchos hispanoamericanos del siglo XIX y anteriores o marginales a la normalidad filosófica.

El diagnóstico reseñado se monta, asimismo, sobre el supuesto de que únicamente comunidades históricas formadas y maduras, autónomas (como serían contemporáneamente el pueblo alemán, el inglés o el francés) pueden dar frutos culturales propios y legítimos, entre los que se encuentra la filosofía. Tal no sería, para Salazar Bondy, el caso de pueblos alienados, dependientes y subdesarrollados, con una "cultura de dominación", como los hispanoamericanos. La autoridad con que Salazar refrenda este parecer es Hegel y su ideas de que "la filosofía es la hija de su tiempo", en base a lo cual afirma: "[L]a filosofía como tal es un producto que expresa la vida de una comunidad, pero que puede fallar en esta función y, en lugar de manifestar lo propio de un ser, puede desvirtuarlo o encubrirlo. Se da según esto el caso de una filosofía inauténtica, de un pensamiento mixtificado" (Ibíd., p. 80).

No obstante la negatividad de su diagnóstico - a saber, no hay "productos filosóficos hispanoamericanos originales" arraigados en una tradición que podamos reconocer, en cuanto local, como propia-, para Salazar Bondy sí es posible darle "originalidad" y "autenticidad" a nuestro pensamiento; y es aquí, justamente, donde el eje normativo de la normalidad filosófica queda tensionado por la asunción de un compromiso político-intelectual. Para asentar esta posibilidad, el peruano se torna contra la autoridad de Hegel, rebatiendo la idea de que la filosofía sea -o pueda ser únicamente- como el búho de Minerva que emprende su vuelo al atardecer; es decir, consumación, explicación a posteriori de lo ya logrado en la historia.

Contra dicha interpretación de la filosofía, Salazar Bondy postula que ella puede ser también, en tanto reflexión comprometida, "la mensajera del alba": el principio de un cambio histórico mediante una toma de conciencia radical proyectada al futuro. En virtud de esto, la filosofía no tiene necesariamente que esperar la cancelación del subdesarrollo y la dominación; es capaz, en efecto, de alcanzar su "autenticidad" como parte del movimiento de superación de los mismos. Puede y debe ser -en palabras del peruano- "una conciencia liberadora de las trabas que impiden la expansión 
antropológica del hispanoamericano que es también la expansión antropológica de toda la especie" (Ibid., p. 90)9.

La respuesta de Zea se afinca justamente en este último punto asentado por Salazar Bondy; y en ella se mantiene -aunque desplazada- la tensión entre profesionalización de la filosofía y compromiso político-intelectual ${ }^{10}$. Su propuesta de "filosofía americana como filosofía sin más" descansa en su interpretación de la filosofía americana -como de toda filosofía posible- en cuanto expresión de la humanidad del hombre: como la capacidad de, mediante el logos, habitar humanamente el mundo (Zea 1996, cap. I). Conforme señala Adriana Arpini, "el planteo zeaniano gana en generalidad lo que pierde en concreción" (Arpini 2003, p. 198), toda vez que al considerar la occidentalización del mundo como un factum, adscribe a una comprensión antropológica, histórica y cultural universal, que prescinde -a contrapelo de la propuesta salazariana- de las diferencias y los conflictos ${ }^{11}$.

$9 \quad$ Sobre la propuesta de Salazar Bondy, Dante Ramaglia comenta: "Entre los aspectos más debatidos de su posición se encuentra la forma esquemática que representa trasladar directamente los caracteres negativos de la estructura socioeconómica al plano cultural, que se traduce en la idea de que sólo mediante la cancelación del subdesarrollo y la dominación se podría llegar a obtener un pensamiento filosófico propio". Sin embargo, el filósofo argentino releva que la incorporación de la estructura material al estudio del pensamiento latinoamericano, es un aporte indesmentible para su posterior desarrollo (Ramaglia 2009, pp. 385-386).

Complementa y matiza lo comentado por Ramaglia, Manuel Ignacio Santos, quien señala que la perspectiva salazariana supone un "papel determinante, aunque no absolutamente", de la base económico-social sobre el ámbito cultural (Santos 1977, p. 35). Si así no fuera, sería impensable postular un ejercicio de la filosofía orientado crítico-dialécticamente a la superación del subdesarrollo y la dominación; en términos coloquiales, al filósofo no le restaría más que "cruzarse de brazos" a esperar las condiciones estructurales que posibiliten un adecuado ejercicio intelectual.

10 La idea de un "compromiso de liberación" por parte de la filosofía cruza la extensa producción de Zea, y se pone de manifiesto, por ejemplo, en el título de su libro de 1991 (Zea 1991).

11 La óptica de Zea se encuentra fuertemente influida, entre otras fuentes, por su interpretación del historicismo gaosiano, el que entronca a su vez con el circunstancialismo orteguiano. Arpini señala que en Zea "El 'hombre' es definido por su logos universal y colocado en una circunstancia, la americana. Circunstancia -agrega Arpini- (...) histórica, desde luego, pero accidental en relación con la naturaleza universal del logos. Se produce, así, un juego de historización-deshistorización del sujeto de la filosofía". Por ello, según la autora, en el mexicano prima una concepción de la historia como "la sucesión de mostraciones circunstanciadas de una naturaleza humana idéntica"; una "visión armónica de la historia donde se esfuman los contornos marcados por las diferencias, los conflictos, los momentos de negación, las rupturas movilizadoras del devenir histórico"; lo cual comporta asumir, a fin de cuentas, un "sentido único de la filosofía, que se va manifestando en las diversas concreciones a lo largo de la historia" (Ibid., pp. 60-61, 65-67).

Complementa lo anterior el parecer de Raúl Fornet-Betancourt, para quien los principales desarrollos de la filosofía latinoamericana (entre ellos los de Zea) se encuentran fuertemente 
Para Zea, por lo tanto, el problema de si tenemos o no filosofía no es otro que el de nuestra humanidad, cuya afirmación constituye en consecuencia el compromiso de los intelectuales y filósofos latinoamericanos con su circunstancia. En virtud de esto, en la óptica de Zea no es casual que nuestra filosofía se inaugure en el siglo XVI, en las figuras de Juan Ginés de Sepúlveda y Bartolomé de Las Casas, con una disputa sobre la condición antropológica de los americanos; humanidad negada por la idea de hombre que tiene el europeo de sí, en cuanto norma o medida de la humanidad o del Hombre.

Tampoco es casual, por lo tanto, que desde Juan Bautista Alberdi, los latinoamericanos nos preguntemos casi obsesivamente por nuestra capacidad para hacer filosofía (o por nuestra cultura e identidad, preguntas que para Zea apuntan a lo mismo), entendiendo dicha capacidad como índice de humanidad ${ }^{12}$. Según Zea, con esta interrogante los latinoamericanos introducen en el ámbito de la filosofía una pregunta extraña, inédita, que el europeo-occidental no se podía plantear en cuanto se consideraba a sí mismo la medida de lo humano, y exigía a los otros rendir cuenta de su estatus antropológico conforme al parámetro occidental.

Así, en la perspectiva del mexicano, la pregunta por la filosofía latinoamericana -o lo que es lo mismo, por nuestra capacidad para filosofar- no es sólo una pregunta válida, sino acaso el tema propio de nuestro pensamiento (Zea 1996, 101). Tal pregunta ya supone, según Zea, hacer una filosofía que parte de y se halla comprometida con nuestra problemática y circunstancia (Ibíd., 105); y con ello, un aporte al acervo filosófico mundial, tradicionalmente monopolizado por Occidente, pero que debe abrirse a las distintas expresiones de lo humano.

En concordancia con la idea de que hay filosofía latinoamericana desde la incorporación de América a la cultura e historia occidental-europeas (entendidas como cultura e historia universales), cobra particular relevancia el estudio de la historia de las ideas, en cuanto disciplina académica que debe registrar los distintos testimonios -asentados en una tradición remontable a Las Casas- de expresión de humanidad del pueblo latinoamericano.

Según Zea, para ser fecunda, esta labor historiográfica debe desprenderse del prejuicio, caro a la "normalidad filosófica", de que las obras propiamente filosóficas son aquellas que adoptan determinados procedimientos escriturales, literarios y argumentativos, como los del tratado filosófico. Se trata, en consecuencia, de enfocar con otros ojos

comprometidos con la idea de "inculturación de la filosofía"; es decir, la afirmación de la historicidad e historización del logos en América Latina, pero considerando como intocable la estructura fundamental de la racionalidad occidental, con valor normativo (FornetBetancourt 2001, p. 62). Véase también Fornet-Betancourt (2004, cap. 2).

12 Como se sabe, Alberdi (1810-1884) fue el primero en plantear, en su texto de 1842 (Alberdi 1993), la pregunta por una "filosofía americana"; situación que lleva a varios filósofos e historiadores de nuestro pensamiento a considerar este texto como "programa fundacional del pensamiento filosófico latinoamericano" (cf. Ramaglia 2009, p. 381, nota). Véase además Roig (2009, cap. XVI). 
nuestro pasado intelectual, en función del futuro que proyectamos realizar; o en otras palabras, de captar lo que de "auténtico" -valga decir, de autoafirmación- hay en la historia de nuestro pensamiento (Ibid., p. 115).

Esto, junto con suponer un compromiso que comporta el rescate de lo positivo de la tradición intelectual latinoamericana -en oposición a la óptica salazariana, para la cual la "autenticidad" y "originalidad" de nuestro pensamiento se encuentran supeditadas a esfuerzos prospectivos-, implica ampliar o descentrar el concepto mismo de filosofía, superando la escisión - tan rotundamente sancionada por Salazar Bondyentre filosofía y pensamiento.

\section{Filosofía americana, entre vindicación identitaria y universalidad}

El segundo núcleo conceptual que me interesa relevar de la controversia -en gran medida bosquejado en el punto anterior, y que en consecuencia viene a desarrollar y complementar lo ya visto; y en que vuelve a hacerse presente la tensión entre ejercicio filosófico profesional y compromiso político-intelectual-, dice relación con el problema de la identidad cultural latinoamericana, y el papel que le correspondería al ejercicio filosófico en su afirmación o construcción.

En términos analíticos, es posible distinguir dos posicionamientos extremos ante esta cuestión, en medio de los cuales habría que ubicar cuidadosamente las posturas de Salazar Bondy y Zea. El primero correspondería a un identitarismo fuerte, para el cual, como respuesta a la herencia cultural eurocéntrica y su filosofía, habría que vindicar lo "propio" y "particular", aun a costa de postular una suerte de mismidad cultural, substancial (en un límite trans o ahistórica), posición que puede fácilmente recaer en un esencialismo o chovinismo. El segundo, a un universalismo igualmente fuerte, para el cual los procesos de "encuentro" o "choque" de culturas, de colonización, mestizaje, hibridación -o como los queramos llamar-apuntarían a una incorporación de la cultura o las culturas locales (para lo que aquí interesa, la americana) a la cultura europeo-occidental entendida como cultura común, universal.

Nuevamente, con todos los resguardos y matices del caso, cabe afirmar que Salazar Bondy coquetea con una suerte de esencialismo cultural, el que se pone de manifiesto en el supuesto de correspondencia entre la madurez de una cultura y la de sus producciones, entre ellas la filosofía. Como veíamos, la asunción de dicho supuesto desempeña un papel destacado en su diagnóstico negativo sobre la tradición filosófica latinoamericana. En sus palabras: "Frente al respaldo con que cuenta la filosofía en Europa, apoyada como está sobre una larga evolución del pensamiento y la cultura tradicionales, en Hispanoamérica no ha encontrado ningún apoyo de la comunidad histórica básica, del fondo popular del espíritu de nuestros pueblos, y vive de la tradición europea, que le es, en este sentido, extraña” (Salazar Bondy 1996, p. 27).

Según hemos constatado, para Salazar Bondy la filosofía "expresa la vida de una comunidad", manifiesta "lo propio de un ser". Sin embargo, en su opinión, esto falla en nuestra América, en la que prima un "hondo defecto de cultura", un "ser 
carencial", un "existir inauténtico", por lo que "vivimos alienados respecto a la propia realidad", en una "representación ilusoria de nuestro ser" (Ibíd., p. 80, 83-84). Los hispanoamericanos, a causa del subdesarrollo, la dependencia y la dominación, nos encontramos alienados, enajenados de la "propia realidad" o del propio "ser". Nuestra identidad cultural, por lo tanto, nos es igualmente ajena, lo que viene a agravarse con la alienación de nuestra producción filosófica, desfondada como se halla respecto de nuestra realidad, y bebiendo de la tradición occidental cual fuente extraña.

A contrapelo de este diagnóstico, según el peruano nuestra filosofía debe, asumiendo un compromiso radical con la superación de nuestra situación deprimida, "sumergirse en la sustancia histórica de nuestra comunidad para buscar en ella el sustento de los valores y categorías que la expresen positivamente y le revelen el mundo" (Ibíd., p. 90). A fin de cuentas, si la filosofía hispanoamericana es inauténtica, esto se debe a la inautenticidad de nuestra cultura -a la distancia al parecer insalvable entre las bases sociales estructurales y nuestras producciones culturales-, por lo que la superación de este estado defectivo demanda una transformación o revolución cultural, a la que puede aportar una filosofía que opte por la liberación.

El identitarismo cultural fuerte de Salazar Bondy se expresa sin ambages en su concepto de cultura, definida en ¿Existe una filosofía de nuestra América? como la "articulación orgánica de las modalidades originales diferenciales de una comunidad, susceptibles de servir de pautas para contrastar la obra histórica de los pueblos y las épocas" (Ibíd., p. 83). En esta apelación a una originalidad cultural, relativa a ciertas modalidades "originales" y "diferenciales" de un colectivo - entiéndase, a lo "propio" y "particular" de éste, no confundible con las manifestaciones culturales de otras asociaciones humanas-, las que por de pronto deben arraigar en "la sustancia histórica" de la misma, la identidad parece corresponderse más a un haber sido o a un ser -o a una concordancia de las producciones culturales con aquéllos-, que a un poder o querer llegar a ser.

Aun cuando no es la intención de este artículo evaluar ni criticar los postulados de los autores, cuanto más bien ponderarlos como puntos de vista que, con toda su complejidad, apuntan a una problematización del estatuto de lo filosófico y de las posibilidades de la filosofía en contextos de enunciación como América Latina-cuestiones que, como problemas, me parecen de una vigencia indesmentible-, conviene contraponer la noción salazariana de identidad cultural con las reflexiones de Marcos García de la Huerta sobre el particular.

Éste menciona: “Identidad significa, por demás, identificación: algo más sutil e indeterminado, más incierto y abierto que un 'ser' inmutable. La identidad -continúa el autor- denota una pertenencia y no puede definirse como una esencia, ni siquiera como algo que se encuentra en acto en las obras, instituciones y costumbres. Viene en alguna medida de lo que ha ido sedimentando el pasado, pero viene así mismo del futuro, de lo que se quiere (y no se quiere) ser, de la tarea o proyecto, que define también profundamente lo que uno es. No se puede impedir que la identidad, dentro de ciertos límites, se haga y rehaga" (García de la Huerta 1999, p. 132). 
En virtud de lo previamente señalado sobre la respuesta de Zea, es de esperar que su posición respecto del problema de la identidad latinoamericana y de la tarea que pueda competer a una filosofía comprometida con su vindicación sea de signo contrario de la Salazar Bondy, ¿mas será por ello menos problemática que la del peruano?

Según veíamos, para Zea hay filosofía americana desde la incorporación de América a la historia y cultura europeas, entendidas como cultura e historia universales. En su óptica, por lo tanto, la tarea de una filosofía latinoamericana comprometida con su circunstancia no es como en Salazar Bondy una afirmación identitaria opuesta al Occidente, sino una inscripción de lo "local", "propio" y "particular" en la universalidad del logos y la cultura occidental-universal. Dicha inscripción es la que permite hablar de un universalismo relativamente fuerte en Zea, toda vez que sin negar las peculiaridades culturales, la mentada inscripción se orienta inevitablemente a borronear los rasgos de localidad y particularismo, por apuntar a una construcción mancomunada y ecuménica de una cultura y una filosofía propiamente universales.

Este punto tiende a clarificarse al considerar que el rescate de la universalidad de la cultura y la filosofía europeo-occidentales por parte de Zea, comporta una importante crítica a la misma. Para Zea, dicha pretensión reviste la forma de una universalidad abstracta, y en definitiva inconducente, pues ha pretendido erigir lo humano -en cuanto común, universal-negando su condición antropológica a quienes no se corresponden al prototipo de humanidad. En sus expresiones históricas, por lo tanto, el despliegue del logos occidental ha enajenado al no occidental, pero también al europeo-occidental, el que se aliena al deshumanizar a los demás.

Contra esta universalidad abstracta y excluyente, la propuesta de Zea apunta a recuperar el sentido positivo del universalismo declarado por Occidente, reconduciéndolo a la construcción de una universalidad concreta; es decir, hacia la confluencia de distintas expresiones de lo humano, que por partir cada una de su circunstancia concreta -justamente, lo que en su opinión habría olvidado el pensar occidental al erigirse en el prototipo de lo humano, en desmedro de las restantes expresiones de humanidadson igualmente valederas. Se trata, por lo tanto, de una universalidad en que quepan las distintas expresiones de lo humano, sin jerarquizaciones ni exclusiones; lo que conlleva, como señala Arpini, a desentenderse en buena medida de la conflictividad de las construcciones culturales presente en Salazar Bondy.

En esta tarea radica la consigna zeaniana de hacer “filosofía sin más", en la que se puede resumir el compromiso que según el mexicano debe adoptar el filósofo latinoamericano con su circunstancia: "hacer pura y simplemente filosofía", desde nuestra circunstancia, que no puede ser sino americana; desde nuestros propios problemas, que por ser problemas de hombres no deben sernos ni "propios" ni "particulares", sino comunes a todos los hombres. Filosofar, a fin de cuentas, bajo la expectativa de que nuestras respuestas son y serán tan valederas como las que se han planteado otros hombres a partir de sus circunstancias.

Así, para Zea, no se trata de buscar una verdad americana ni de afirmar una identidad que nos sea propia (lo que en buena medida encontramos en la propuesta salazariana), sino una verdad válida para todos los hombres, una verdad a secas y por 
tanto universal; hacer filosofía, pues lo americano -si ello tiene alguna importanciavendrá por añadidura (Zea 1996, p. 44).

\section{Desplazamientos categoriales}

Concluiré refiriéndome al que probablemente sea el punto más controversial -y por ello más sugestivo e interesante- de la discusión de Salazar Bondy y Zea. Conforme hemos podido observar, las posturas de los autores difieren en puntos sustantivos. Nos detuvimos, en primer lugar, en las distintas interpretaciones adoptadas respecto del estatuto de lo que pudiera llamarse filosofía latinoamericana: si es ella una labor remontable a una tradición o si bien es un proyecto prospectivo por realizar. En segunda instancia, en sus posicionamientos respecto del rol que le cabría al ejercicio de la filosofía en el subcontinente en la consolidación o afirmación de una identidad propia y particular, o si más bien ha de conducir sus esfuerzos a una incorporación en la presunta universalidad de la cultura y el pensar occidentales. En tales diferendos procurábamos mostrar, además, que revestía diversas formas la tensión entre el ejercicio filosófico académico normalizado y el compromiso político-intelectual, apuntando este último hacia distintos objetivos.

Corresponde ahora señalar que los diferendos registrados se explican y al mismo tiempo se profundizan, al considerar que la respuesta de Zea comporta un desplazamiento de las categorías en que se monta el diagnóstico de Salazar Bondy sobre la historia y la situación del filosofar hispanoamericano hacia fines de la década del 60; a saber, peculiaridad, autenticidad y originalidad ${ }^{13}$. Esto, que si bien es propio del trabajo filosófico -y nos permite comprender las reelaboraciones que hacen los autores sobre los postulados de la tradición, al modo de lecturas y deslecturas, propias del interpretar- en un extremo podría ser ponderado como renuncia o elusión de la discusión; pues nada nos asegura que, a fin de cuentas, cada quien se esté refiriendo a alguna cosa distinta, o que en el fondo estemos concurriendo a un "diálogo de sordos".

13 Estos desplazamientos categoriales - como los hemos querido llamar-están registrados en la bibliografía que ha abordado la polémica. Adriana Arpini, por ejemplo, sostiene que "las cuestiones planteadas por Augusto Salazar Bondy no resultan cabalmente asumidas por Leopoldo Zea", por cuanto su respuesta parte de supuestos distintos que los del peruano, y de interpretaciones diversas respecto de las categorías centrales de éste (Arpini 2003, p. 67). Helio Gallardo es aun más severo, pues afirma: "En verdad, Zea no asume el cuestionario de Salazar Bondy"; es decir, no da respuesta a las preguntas por él planteadas; o en caso de hacerlo, sus contestaciones suponen desplazamientos tales que difícilmente son reconocibles como réplicas a las preguntas del peruano (Gallardo 1974, p. 195, nota). Dante Ramaglia matiza en alguna medida el asunto, al sostener que no obstante lo mencionado, Salazar Bondy y Zea coinciden en la consideración de la dependencia como fenómeno que interpela a la filosofía latinoamericana, aun cuando difieren, nuevamente, respecto de la importancia de su superación para la conformación de la misma (Ramaglia 2009, p. 387). 
Salazar Bondy procura definir con bastante exactitud los criterios de su evaluación. Afirma que una filosofía es original en cuanto aporta ideas y planteos nuevos, distinguibles como creaciones, como "construcciones conceptuales inéditas de valor reconocido". Por su parte, sostiene que un producto filosófico es auténtico (o genuino) en cuanto se da propiamente como tal y no como algo falseado o mixtificado. Finalmente, por peculiaridad entiende los rasgos histórico-culturales diferenciales de un producto filosófico, al modo de un tono local o personal, que como tal no implica ni originalidad ni autenticidad (Salazar Bondy 1996, p. 72).

Para el peruano, es evidente que el pensamiento hispanoamericano cumple el criterio de peculiaridad, dado que son reconocibles algunas modalidades presentes en nuestra tradición intelectual, que la distinguen de otras. Sin embargo -y he aquí el punto para él decisivo- no es así respecto de la originalidad y la autenticidad. Estos últimos criterios, que constituyen la base de su evaluación negativa de nuestra filosofía, son fuertemente normativos y se hallan íntimamente vinculados, a la vez que se encuentran comprometidos con supuestos fuertes, como las directrices de la filosofía occidental contemporánea de corte académico, y su propia interpretación de las relaciones entre cultura y filosofía.

Para Salazar Bondy, un producto es auténtica (o genuinamente) filosófico en cuanto difiere de uno que no lo es, lo que supone una circularidad en la argumentación, cuando no una tautología. En efecto señala: "la filosofía de Kant es genuina y (...) un discurso espiritualista es seudofilosofía” (Ídem.). La aclaración, como vemos, no hace sino oscurecer el asunto, pues sanciona -en base al presuntamente indiscutible carácter filosófico de la obra kantiana, es decir, mediante la apelación a una autoridad consagrada por la filosofía académica- la separación entre auténtica filosofía y una que no lo es.

Junto con ello, su concepto de originalidad parece comprometido, al menos parcialmente, con la noción romántica de genio, según la cual solo a algunos insignes pensadores les estaría dado realizar aportes verdaderos, novedosos y reconocibles como tales. Pero solo parcialmente -conviene matizar-, pues tal capacidad radicaría asimismo en que los autores se encuentren adecuadamente asentados en comunidades históricas maduras, autónomas, dueñas de sí, con una identidad consolidada.

Según hemos apuntado en momentos anteriores, para el peruano la filosofía hispanoamericana es inauténtica-entiéndase, filosofía solo en apariencia- a causa de la inautenticidad de nuestra cultura, catalogada por el autor, a causa de la estructural situación de subdesarrollo y dependencia social y económica, como una "cultura de dominación". Ante esta situación defectiva-medida al trasluz de la supuesta autenticidad cultural de los países industriales avanzados-, el pensador local, según Salazar Bondy, construye una imagen ilusoria de sí y de su comunidad, la que no le permite ser original; es decir, expresar con categorías novedosas su propia y peculiar visión del mundo y de la historia. Sin embargo, y como veíamos, para Salazar Bondy nuestra seudofilosofía puede llegar a ser filosofía propiamente tal -auténtica y original-, en la medida en que, comprometiéndose con la superación del estado deprimido de nuestra cultura, opte, cual "mensajera del alba", por la liberación. 
Pues bien, cuando sostengo que en La filosofia americana como filosofía sin más Zea lleva a cabo una serie de desplazamientos categoriales, me refiero puntualmente al modo en que resignifica las nociones salazarianas de peculiaridad, autenticidad y originalidad, y sus mutuas relaciones.

Estas resignificaciones reposan, según lo visto, en la propia interpretación zeaniana de la filosofía en general, y específicamente de sus posibilidades en contextos de enunciación distintos a los de los países occidentales; vale decir, la filosofía como actividad en que tiene lugar una disputa por el reconocimiento de la condición antropológica de aquellos a quienes el despliegue de la modernidad occidental la había negado. Dicha interpretación supone, al mismo tiempo, un posicionamiento distinto que el del peruano, respecto del problema de si la filosofía latinoamericana es un proyecto o un repertorio que cuenta con una tradición que se debe rescatar, sobre la disyuntiva entre identidad y universalidad, y sobre el compromiso político que corresponde al filosofar en América Latina.

Podemos constatar un primer desplazamiento importante en la resignificación llevada a cabo por Zea respecto de las relaciones entre los criterios del diagnóstico de Salazar. Como veíamos, para éste la peculiaridad significa un tono personal o local, que no comporta autenticidad u originalidad de un producto filosófico. Zea resignifica las nociones de peculiaridad, autenticidad y originalidad, al punto de hacerlas convergentes, y haciendo de dicha convergencia el pivote de su enfoque positivo de nuestra filosofía. Según ha destacado Helio Gallardo, Zea reenfoca el tema de la peculiaridad al entenderla, ya no como los rasgos histórico-culturales diferenciales de un producto filosófico, sino poniendo el énfasis en 'lo 'peculiar' que resulta preguntar por la posibilidad de nuestra filosofía” (Gallardo 1974, p. 194).

Una vez obrado este desplazamiento, la peculiaridad deja de ser, como en Salazar Bondy, un aspecto defectivo, por cuanto en sus formas de expresión discursiva nuestros pensadores han tratado de afirmar, a su modo y estilo propios, su condición como sujetos pensantes y, por lo tanto, nuestra condición humana. Así, a contrapelo de la perspectiva del peruano, es esta peculiaridad la que funda la autenticidad y originalidad del filosofar, en la medida en que cada pensador, cada comunidad, encuentra sus modos discursivos de expresar el mundo y expresarse a sí mismo.

Ya hemos destacado que el cultivo de la historia de las ideas tiene para Zea, entre otros cometidos, registrar positivamente lo propio de nuestra filosofía en su decurso histórico (lo que Salazar Bondy denomina peculiaridad), desprendiéndose de parámetros impuestos externamente, como los de la filosofía europeo-occidental de corte académico. Dicho campo disciplinar, según Zea, ha de mostrar que nuestro pensamiento sí ha sido, a su modo propio, auténtica filosofía -y no una seudofilosofía, una mixtificación-, en cuanto ha sido el intento del hombre americano por responder a los problemas concretos de su circunstancia histórica.

Aquí, como ha señalado Adriana Arpini, autenticidad e inautenticidad dejan de hacer relación al vínculo entre un producto filosófico y las bases materiales de una sociedad, para apuntar más bien a la afirmación o negación de lo humano. En esta nueva perspectiva, inauténtica es, para Zea, una filosofía que adopta una idea de hombre que 
niega a los hombres concretos. Esto le permite afirmar que parte de la filosofía occidental misma ha sido inauténtica, y que la conquista de la autenticidad de nuestra filosofía no depende de una superación del subdesarrollo, sino de una toma de conciencia del propio estatuto antropológico (Arpini 2003, p. 66).

Reenmarcada así la cuestión, la filosofía americana ha sido y es, al tiempo que peculiar, auténtica y original. He aquí un nuevo desplazamiento categorial, pues la originalidad ya no radica, como en Salazar Bondy, en la posibilidad de decir algo inédito, sino en la capacidad de incorporar la tradición para resolver nuestros problemas, importando poco si las "herramientas" conceptuales han sido tomadas de Europa o de otro lugar. Esto reposa en el supuesto de que toda asimilación implica un cambio, una traducción, una adopción de lo ajeno -que por ser humano no nos puede ser extraño- a las propias circunstancias, por lo que pierde sentido la disyunción entre copia y originalidad ${ }^{14}$.

Zea postula, en efecto, una "autenticidad de la asimilación”, en la que se juegan la autenticidad y la originalidad de nuestro filosofar (Zea 1996, pp. 34, 39). Es por ello que afirma: "Auténtica ha tenido que ser la filosofía que ha puesto en duda la validez de esta interrogación deshumanizante [de una parte de la filosofía occidental que ha cuestionado nuestra condición antropológica], como la que se ha esforzado por demostrar nuestra humanidad, la que se pregunta por la posibilidad de la existencia de una cultura igualmente nuestra y de una filosofía originada entre nosotros" (Ibíd., p. 115).

Para el mexicano, en consecuencia, la originalidad de toda filosofía radica en partir de la propia circunstancia para trascenderla hacia lo plenamente humano, común y universal; partir de lo que se ha sido y de lo que se es para arribar a lo que se quiere ser. En este sentido, a pesar de todos los diferendos, Zea estima que el libro de Salazar Bondy -al igual que todos los que se han preguntado por la filosofía latinoamericanaes expresión de nuestro filosofar, de su peculiaridad, autenticidad y originalidad; del problema, en definitiva, en que nos coloca nuestra condición como subordinados respecto de la cultura occidental (Ibíd., p. 88).

\section{Referencias bibliográficas}

Alberdi, Juan Bautista (1993), "Ideas para un curso de filosofía contemporánea" [1842]. Zea, Leopoldo (comp.), Fuentes de la cultura latinoamericana I. México: FCE; pp. 145-151.

Arpini, Adriana (2003), "La polémica entre Augusto Salazar Bondy y Leopoldo Zea. Una revisión crítica del historicismo en América Latina”. Arpini, Adriana

14 Podríamos agregar que no solo pierde sentido la disyunción, sino que para Zea la misma no existe. Así parece concebirlo Helio Gallardo, para quien "[e]n el contexto zeaniano, (...) la pregunta por la originalidad del filosofar carece de sentido, no es una pregunta". (Gallardo 1974, p. 195, nota) 
(comp.), Otros discursos. Estudios de Historia de las Ideas Latinoamericanas. Mendoza: UNCuyo; pp. 45-70.

(2016), "La polémica entre Augusto Salazar Bondy y Leopoldo Zea. Una bisagra en la historia de las ideas latinoamericanas". Filosofia, crítica y compromiso en Augusto Salazar Bondy. Lima: Fondo Editorial del Congreso del Perú; pp. 179-203.

Cerutti Guldberg, Horacio (2006) [1983], "La polémica entre Augusto Salazar Bondy y Leopoldo Zea”. Filosofía de la liberación latinoamericana. México: FCE; pp. 263-273.

Devés, Eduardo (2003-2004), El pensamiento latinoamericano en el siglo XX, 3 tomos. Buenos Aires/Santiago: Biblos/DIBAM.

Fornet-Betancourt, Raúl (2001), Transformación intercultural de la filosofía. Bilbao: Desclée de Brouwer.

(2004), Crítica intercultural de la filosofía actual. Madrid: Trotta.

Gallardo, Helio (1974), "El pensar en América Latina. Introducción al problema de la conformación de nuestra conciencia: A. Salazar Bondy y L. Zea", Revista de Filosofía de la Universidad de Costa Rica, vol. XII, (No 35): 183-210.

García De La Huerta, Marcos (1999), Reflexiones americanas. Ensayos de IntraHistoria. Santiago: LOM Ediciones.

(2014), "Filosofía latinoamericana y 'diálogo intercultural”, en García de la Huerta, Marcos y Carlos Ruiz Schneider, Construcción de identidad, creación de sentido. Santiago: Universitaria; pp. 77-95.

Giannini, Humberto (2004) [1987], La "reflexión cotidiana”. Hacia una arqueología de la experiencia. Santiago: Universitaria.

Molina, Enrique (1953), La filosofia en Chile en la primera mitad del siglo XX. Notas y recuerdos. Santiago: Nascimento.

Olmedo, Francisco (1972), "El problema de la filosofía latinoamericana". El Guacamayo y la Serpiente $\mathrm{N}^{0} 5$.

Ossandón, Carlos (1984), 'El concepto de 'normalidad filosófica' en Francisco Romero". Hacia una filosofia latinoamericana. Santiago: Nuestra América; pp. 67-91.

Ramaglia, Dante (2007), “Alejandro Korn y la 'normalización' de la filosofía”. Jalif, Clara (ed.), Argentina, entre el optimismo y el desencanto. Mendoza: UNCuyo/ Qellqasqa; pp. 63-83.

(2009), "La cuestión de la filosofía latinoamericana". Dussel, Enrique, Eduardo Mendieta, Carmen Bohórquez, ed., El pensamiento filosófico latinoamericano, del Caribe y "latino" (1300-2000): historia, corrientes, temas y filósofos. México: Siglo XXI/CREFAL; pp. 377-398.

Roig, Arturo Andrés (2009) [1981], Teoría y crítica del pensamiento latinoamericano. Buenos Aires: Una Ventana.

Romero, Francisco (1952), Sobre la filosofia en América. Buenos Aires: Raigal. 
Salazar Bondy, Augusto (1996) [1968], ¿Existe una filosofía de nuestra América? Decimotercera edición. México D.F.: Siglo XXI.

Sánchez, Cecilia (1992), Una disciplina de la distancia. Institucionalización universitaria de los estudios filosóficos en Chile. Santiago: CERC/CESOC.

Santos, Manuel Ignacio (1977), "La filosofía en la actual coyuntura histórica Latinoamericana. Notas críticas sobre la filosofía latinoamericana como filosofía de la liberación". Pucará, № 2: 13-46.

Santos Herceg, José (2010), Conflicto de representaciones. América Latina como lugar para la filosofía. Santiago: FCE.

(2012), ¿Qué se dice cuando se dice filosofía latinoamericana?”. Revista de Filosofia, vol. 68: 65-78.

Zea, Leopoldo (1991), La filosofía como compromiso de liberación. Caracas: Biblioteca Ayacucho.

(1996) [1969], La filosofía americana como filosofía sin más. Decimosexta edición. México D.F.: Siglo XXI. 